\title{
Light-Induced Surface Reactions at the Bismuth Vanadate/Potassium Phosphate Interface
}

\author{
Marco Favaro $^{*}{ }^{a}$, Fatwa F. Abdi ${ }^{a}$, Marlene Lamers ${ }^{a}$, Ethan J. Crumlin ${ }^{b}$, Zhi Liu ${ }^{c, d}$, \\ Roel van de $\mathrm{Krol}^{a}$ and David E. Starr ${ }^{*}$
}

${ }^{a}$ Institute for Solar Fuels, Helmholtz-Zentrum Berlin für Materialien und Energie GmbH, Berlin, 14109, Germany.

${ }^{b}$ Advanced Light Source, Lawrence Berkeley National Laboratory, Berkeley, CA 94720, USA.

${ }^{c}$ State key Laboratory of Functional Materials for Informatics, Shanghai Institute of Microsystem and Information Technology, Chinese Academy of Sciences, Shanghai 200050, People's Republic of China.

${ }^{d}$ Division of Condensed Matter Physics and Photon Science, School of Physical Science and Technology, ShanghaiTech University, Shanghai 200031, China.

*Correspondence should be addressed to M. Favaro (marco.favaro@helmholtz-berlin.de) and D. E. Starr (david.starr@helmholtz-berlin.de).

\begin{abstract}
Bismuth vanadate has recently drawn significant research attention as a lightabsorbing photoanode due to its performance for photoelectrochemical water splitting. In this study, we use in situ ambient pressure X-ray photoelectron spectroscopy with "Tender" Xrays $(4.0 \mathrm{keV})$ to investigate a polycrystalline bismuth vanadate $\left(\mathrm{BiVO}_{4}\right)$ electrode in contact with an aqueous potassium phosphate (KPi) solution at open circuit potential under both dark and light conditions. This is facilitated by the creation of a 25 to 30 nanometers thick electrolyte layer using the "dip-and-pull" method. We observe that under illumination bismuth phosphate forms on the $\mathrm{BiVO}_{4}$ surface leading to an increase of the surface negative charge. The bismuth phosphate layer may act to passivate surface states observed in photoelectrochemical measurements. The repulsive interaction between the negatively charged surface under illumination and the phosphate ions in solution causes a shift in the distribution of ions in the thin aqueous electrolyte film, which is observed as an increase in their photoelectron signals.
\end{abstract}

Interestingly, we find that such changes at the $\mathrm{BiVO}_{4} / \mathrm{KPi}$ electrolyte interface are reversible upon returning to dark conditions. By measuring the oxygen 1s photoelectron peak intensities from the phosphate ions and liquid water as a function of time under dark and light conditions, we determine the timescales for the forward and reverse reactions. Our results provide direct evidence for lightinduced chemical modification of the $\mathrm{BiVO}_{4} / \mathrm{KPi}$ electrolyte interface. 


\section{Introduction}

Chemical fuels produced using sunlight is a potential way to store solar energy and therefore mitigate its intermittency. 1, 2, 3, 4, 5, 6, 7 To date, solar fuel research has predominantly focused on solar water splitting to generate hydrogen, which can be used both as a primary energy source (in power plant or automobile-based fuel cells) and as a chemical feedstock for the production of

synthetic fuels. 7, 8, 9, 10, 11, 12, 13, 14 During photoelectrochemical water splitting, sunlight absorbed by a semiconductor generates photo-excited charge carriers, (electrons in the conduction band (CB) and holes in the valence band (VB)) that drive electrochemical reactions at the semiconductor/aqueous electrolyte interface. The electrons drive hydrogen evolution at the cathode while holes drive oxygen evolution at the anode. Since the rate of photoelectrochemical water splitting is determined by charge separation and hole transfer from the anode to the electrolyte, research efforts focus mainly on photoanode materials for oxygen evolution.

Among the promising photoanode materials for solar water splitting, monoclinic clinobisvanite bismuth vanadate $\left(\mathrm{BiVO}_{4}\right)$ has recently drawn significant research attention due to its high photo-activity, good catalytic properties and reasonable stability. ${ }^{7,}$ 9, 10, 15, 16, 17, 18, 19 The valence band maximum (VBM) of $\mathrm{BiVO}_{4}$, an $n$-type semiconductor, is lower than the oxygen evolution potential $(+1.23 \mathrm{~V}$ vs. $\mathrm{NHE}$ at $\mathrm{pH} 0)$, allowing holes to be efficiently transferred to the electrolyte and subsequently oxidize water. However, charge carrier recombination at the semiconductor/electrolyte interface limits the efficiency of $\mathrm{BiVO}_{4}$ based devices by eliminating holes before they can oxidize water. ${ }^{20,21}$ Surface states induced by surface reactions can act as electron and hole traps and enhance the recombination rate. Moreover, surface states are wellknown to cause Fermi level pinning leading to reduced photovoltages and a decrease in the efficiency of the device. ${ }^{22}$ Therefore, a detailed understanding of the chemical composition of the semiconductor/aqueous electrolyte interface and its dependence on specific conditions (applied potential and illumination) would provide valuable input for the optimization of photoanode material for oxygen evolution. ${ }^{23,24}$

In this study, we investigate a polycrystalline, un-doped $\mathrm{BiVO}_{4}$ photoanode/potassium phosphate (KPi) aqueous electrolyte interface. Capacitive current scans reveal that a surface state present on undoped $\mathrm{BiVO}_{4}$ in the dark is quenched under illumination. Using in situ ambient pressure hard X-ray photoelectron spectroscopy (AP-HAXPES) with $4.0 \mathrm{keV}$ excitation energy, we have investigated chemical transformations at the $\mathrm{BiVO}_{4} / \mathrm{KPi}$ interface induced by solar light at the half-cell open circuit potential. To conduct such measurements, a 24 to 32 nanometers thick 
KPi aqueous electrolyte layer is created by the "dip-and-pull” method. ${ }^{25,}$ 26, 27, 28, 29, 30, 31 We show that a thin layer of bismuth phosphate $\left(\mathrm{BiPO}_{4}\right)$ is formed on the $\mathrm{BiVO}_{4}$ surface under illumination which likely acts to passivate surface states. Time dependent AP-HAXPES measurements suggest that an increase of the surface negative charge as a function of the illumination time, as measured by a change in the half-cell open circuit potential, is correlated with the formation of the $\mathrm{BiPO}_{4}$ layer. The repulsive interaction between the negatively charged surface and the phosphate anions in the electrolyte solution causes a change in the distribution of ions in the aqueous electrolyte layer. This is observed as an increase in the photoemission signal from the ions in solution. Interestingly, we find that such changes are reversible upon returning to dark conditions. Our findings provide direct evidence of light-induced chemical modification of the $\mathrm{BiVO}_{4} / \mathrm{KPi}$ electrolyte interface.

\section{Experimental}

\section{Sample preparation}

Undoped $\mathrm{BiVO}_{4}$ thin films were prepared by spray pyrolysis on FTO-coated glass (TEC-15, Pilkington). Detailed information on the spray pyrolysis setup and precursor solutions can be found in our previous report. ${ }^{32}$ In short, the FTO substrate was placed on a hot plate $\left(450^{\circ} \mathrm{C}\right)$ during the spray pyrolysis of $\mathrm{BiVO}_{4} .100$ cycles of deposition were performed with a rate of $\sim 1 \mathrm{~nm}$ per cycle. Prior to the $\mathrm{BiVO}_{4}$ deposition, $5 \mathrm{~mL}$ solution of $0.1 \mathrm{M}$ $\mathrm{SnCl}_{4}\left(99 \%\right.$, Acros Organics) in ethyl acetate (99.5\%, J.T. Baker) was sprayed on the FTO substrate to form a $\mathrm{SnO}_{2}$ interfacial layer $(\sim 80 \mathrm{~nm})$. Finally, the undoped $\mathrm{BiVO}_{4} / \mathrm{SnO}_{2} / \mathrm{FTO}$ sample was post annealed for 2 hours at $450^{\circ} \mathrm{C}$ under the flow of technical air $\left(80 \% \mathrm{~N}_{2} / 20 \% \mathrm{O}_{2}\right)$. The surface morphology of the obtained samples was studied by atomic force microscopy in tapping mode, as reported in Figure S1.

\section{Photoelectrochemical measurements}

The chemicals were high purity reagents and used without further purification. MilliQ water (DI, $\rho=18.2$ $\mathrm{M} \Omega \cdot \mathrm{cm}), \mathrm{K}_{2} \mathrm{HPO}_{4}$ and $\mathrm{KH}_{2} \mathrm{PO}_{4}$ (99.95\% and 99.99\%, Aldrich, respectively) were used as the solvent and supporting electrolyte, respectively. The $0.1 \mathrm{M} \mathrm{KPi}$ solution was made by dissolving $0.062 \mathrm{~mol}$ of $\mathrm{K}_{2} \mathrm{HPO}_{4}$ and $0.038 \mathrm{~mol}$ of $\mathrm{KH}_{2} \mathrm{PO}_{4}$ per liter of MilliQ water. The measured $\mathrm{pH}$ of the KPi solution was between 7.0 and 7.1.

The counter electrode (CE, Pt polycrystalline foils, 99.99\%, thickness $0.5 \mathrm{~mm}$, Aldrich) was polished to a mirror finish with silicon carbide paper of decreasing grain size (Struers, grit: 2400 and 4000). The CE was then cleaned with two cycles of ultrasonic treatment in a mixture of MilliQ water/ethanol (Aldrich, 1:1) for 10 min. A third ultrasonic cleaning was then conducted in pure MilliQ water for $15 \mathrm{~min}$, followed by a thorough rinsing and drying in streaming $\mathrm{N}_{2}$ (g). The reference electrode (RE), was a miniaturized leak-less saturated $\mathrm{Ag} / \mathrm{AgCl} / \mathrm{Cl}^{-}$(sat) $\mathrm{RE}$ (ET072-1, eDAQ, standard electrode potential $E^{\circ}{ }_{\mathrm{Ag} / \mathrm{AgCl} \text { (sat.) }}=+199 \mathrm{mV}$ with respect to the normal hydrogen electrode, NHE). For better comparison to the literature, the potentials reported in this work are referred to the reversible hydrogen electrode (RHE), which is related to the $\mathrm{Ag} / \mathrm{AgCl}^{-\mathrm{Cl}^{-}}{ }_{\text {(sat.) }}$ electrode and the electrolyte $\mathrm{pH}$ by the following relation:

$$
E_{\mathrm{RHE}}=E_{\mathrm{Ag} / \mathrm{AgCl}(\text { sat.) }}+E_{\mathrm{Ag} / \mathrm{AgCl} \text { (sat.) }}^{\circ}+0.0591 \cdot \mathrm{pH}
$$


Cyclic voltammetry (CV) measurements were conducted at room temperature at a scan rate of $10 \mathrm{mV} \mathrm{s}^{-1}$ in a $0.1 \mathrm{M} \mathrm{KPi}$ solution. Capacitive current scans were used to determine the surface charge and the $\mathrm{BiVO}_{4} / \mathrm{KPi}$ electrolyte interfacial differential capacitance (i.e. capacitance as a function of the applied potential). The measurements were carried out at room temperature. The charge was determined by integrating the area of the cyclic voltammetry curves (taken with a scan rate of $50 \mathrm{mV} \mathrm{s}^{-1}$ ) within a $20 \mathrm{mV}$ potential window centered at each chosen potential. $^{28,33}$ The results are reported in Figure S2.

\section{In situ hard X-ray photoelectron spectroscopy measurements}

\section{Beamline 9.3.1 and AP-HAXPES experimental details}

The source for beamline 9.3.1 at the Advanced Light Source (ALS) of Lawrence Berkeley National Laboratory is a bending magnet. A Si(111) double crystal monochromator (DCM) provides an energy range between $2.0 \mathrm{keV}$ and $7.0 \mathrm{keV}$ (i.e., the "tender" X-ray range, denoted as "hard" throughout the text to be consistent with the acronym HAPXES). The minimum X-ray spot size on the sample is $0.7 \mathrm{~mm}(\mathrm{v}) \times 1.0 \mathrm{~mm}(\mathrm{~h})$. All spectra were taken with a photon energy of $4.0 \mathrm{keV}$, at room temperature and in normal emission (NE). The pressure in the experimental chamber was kept at the equilibrium vapor pressure of the KPi electrolyte solution at room temperature. The pass energy of the Scienta analyzer (R4000 HiPP-2) was set to $200 \mathrm{eV}$. A step size of $100 \mathrm{meV}$ and a dwell time of 300 ms was used. Under these conditions, the total resolution (X-ray plus analyzer) was equal to about $700 \mathrm{meV}$ at 4.0 $\mathrm{keV}$. To limit evaporation from the electrochemical cell a large volume $(\sim 500 \mathrm{~mL})$ of outgassed pure water was introduced in the analysis chamber. Binding energy $(\mathrm{BE})$ scale calibration was done by using the $\mathrm{Au} 4 \mathrm{f}_{7 / 2}(\mathrm{BE}=$ $84.00 \mathrm{eV}$ ) photoelectron peak position and the Fermi edge taken with a clean gold polycrystalline surface as reference values measured under all the experimental conditions. Spectral fitting was carried out using a DoniachŠunjić shape for the $\mathrm{Au} 4 \mathrm{f}$ and $\mathrm{Bi} 4 \mathrm{f}$ photoelectron peaks, whereas symmetric Voigt functions $(\mathrm{G} / \mathrm{L}$ ratio ranging from 85/15 to 75/25) were used to fit the O 1s (after Shirley background subtraction). During the fitting procedure, the Shirley background was optimized together with the spectral components. ${ }^{34,35,36}$ Finally, chi-square $\left(\chi^{2}\right)$ minimization was ensured by the use of a nonlinear least squares routine, with increased stability over simplex minimization.

\section{"Dip and pull” method and in situ measurements}

Three electrodes $\left(\mathrm{BiVO}_{4} \mathrm{WE}, \mathrm{Ag} / \mathrm{AgCl} / \mathrm{Cl}^{-}{ }_{\text {(sat.) }} \mathrm{RE}\right.$ and Pt foil $\left.\mathrm{CE}\right)$ were mounted in a PEEK electrode housing that was attached to a multi-axis manipulator. The working electrode (WE), counter electrode (CE), and reference electrode (RE) were connected to an external potentiostat/galvanostat (Biologic SP 300) to perform in situ electrochemical measurements. During operation, the WE and the electron energy analyzer were commonly grounded.

Prior its introduction into the experimental chamber, the $0.1 \mathrm{M} \mathrm{KPi}$ aqueous electrolyte was outgassed for at least $30 \mathrm{~min}$ at low pressure (between 10 and 20 Torr) in a dedicated off-line chamber. The pH of the $0.1 \mathrm{M} \mathrm{KPi}$ solution was measured to be between 7.0 and 7.1. After degassing the electrolyte solution, it was placed into the APHAXPES chamber, the pressure was carefully decreased to just below the equilibrium vapor pressure of the $0.1 \mathrm{M}$ $\mathrm{KPi}$ solution at room temperature, and then pumping was stopped and the chamber pressure drifted up to the equilibrium vapor pressure of the KPi electrolyte solution at room temperature (approximately 17 Torr).

To create the $\mathrm{BiVO}_{4} / \mathrm{KPi}$ electrolyte interface (WE/electrolyte), all three electrodes were immersed deeply into the electrolyte. They were then slowly extracted from the electrolyte solution by raising the manipulator at a slow and constant rate. Following this procedure, a thin layer of the KPi aqueous electrolyte film is formed on the electrode surface (typical values in this study are 24 to $32 \mathrm{~nm}$, see below); the $\mathrm{BiVO}_{4}$ working electrode was then positioned at the intersection of the X-ray beam and the focal point of the hemispherical electron analyzer (HEA), thereby allowing AP-HAXPES measurements of the $\mathrm{BiVO}_{4} / \mathrm{KPi}$ electrolyte interface. During the measurements, the bottom parts of the electrodes remained submerged in the bulk KPi electrolyte solution, in order to ensure electrical continuity between the thin electrolyte layer on the $\mathrm{BiVO}_{4} \mathrm{WE}$ surface and the bulk KPi electrolyte. 
To illuminate the $\mathrm{BiVO}_{4} / \mathrm{KPi}$ system during the AP-HAXPES experiments, a solar simulator (Asahi Spectra, HAL-C100) was used as a light source (sun irradiation: $1 \mathrm{sun}=75 \mathrm{~mW} \mathrm{~cm}^{-2}$ ). The light source, whose power density was distributed over a spectral range from $350 \mathrm{~nm}$ to $1100 \mathrm{~nm}$, was placed at a distance of about $25 \mathrm{~cm}$ from the $\mathrm{BiVO}_{4} \mathrm{WE}$ (front illumination configuration), and the light was directed to the sample through a standard CF35 windowed flange (glass thickness: $3 \mathrm{~mm}$ ). Under such conditions, the maximum power was reached in a $10 \times 10 \mathrm{~mm}$ sample area, with an average power density of about $69 \mathrm{~mW} \mathrm{~cm}^{-2}(\sim 0.92$ sun$)$ at the WE surface.

\section{Results}

$\mathrm{BiVO}_{4}$ film morphology

The surface morphology of the $\mathrm{BiVO}_{4}$ film was studied with atomic force microscopy (AFM, see inset in Figure 1 and also SI Figure S1) which provided a root mean square (RMS) roughness of about $25 \mathrm{~nm}$ over an area of $2 \times 2 \mu \mathrm{m}^{2}$.

\section{Photoelectrochemical measurements on $\mathrm{BiVO}_{4}$}

To determine the $\mathrm{BiVO}_{4} / \mathrm{KPi}$ electrolyte interface capacitance $\left(\mathrm{C}_{\mathrm{BiVO} / / \mathrm{KP}}\right)^{37}$ as a function of the applied potential under dark and light conditions the electrochemical capacitive current scan method was used (see Experimental section and Figure S2 for the capacitive current determination under dark and light conditions via cyclic voltammetry). The capacitance determined under dark conditions exhibits a pronounced deviation from the typically observed asymptotic decay, which reflects a decrease in space charge width with increasing applied potential (Figure 1). Instead it shows a peak centered at about $+0.7 \mathrm{~V}$ vs. RHE. Such a peak has been previously characterized as evidence for a surface state by Bard et al. ${ }^{22}$ The surface state can cause unpinning of the band edges and, consequently, Fermi edge pinning across the $\mathrm{BiVO}_{4} / \mathrm{KPi}$ electrolyte interface and can have a detrimental effect on device efficiency. ${ }^{20,}{ }^{22}$ Figure 1 shows that to unpin the Fermi edge in dark conditions the applied potential must exceed $\sim 1 \mathrm{~V}$ vs. RHE. This is consistent with previous reports for undoped $\mathrm{BiVO}_{4}{ }^{20}{ }^{20}$ Interestingly, when we illuminate the $\mathrm{BiVO}_{4}$ with solar light, the feature associated with the surface state in the capacitance versus applied potential plot disappears (only the typical asymptotic decay remains, see Figure 1) but reappears after returning to dark conditions. This suggests that the surface state present on the pristine undoped $\mathrm{BiVO}_{4}$ in dark conditions is passivated upon illumination.

Surface state passivation on $\mathrm{BiVO}_{4}$ photoanodes has been previously observed when depositing catalyst layers. For example, using intensity modulated photocurrent spectroscopy to monitor the rates of charge transfer and recombination, Zachäus et al. observed a decrease in the 


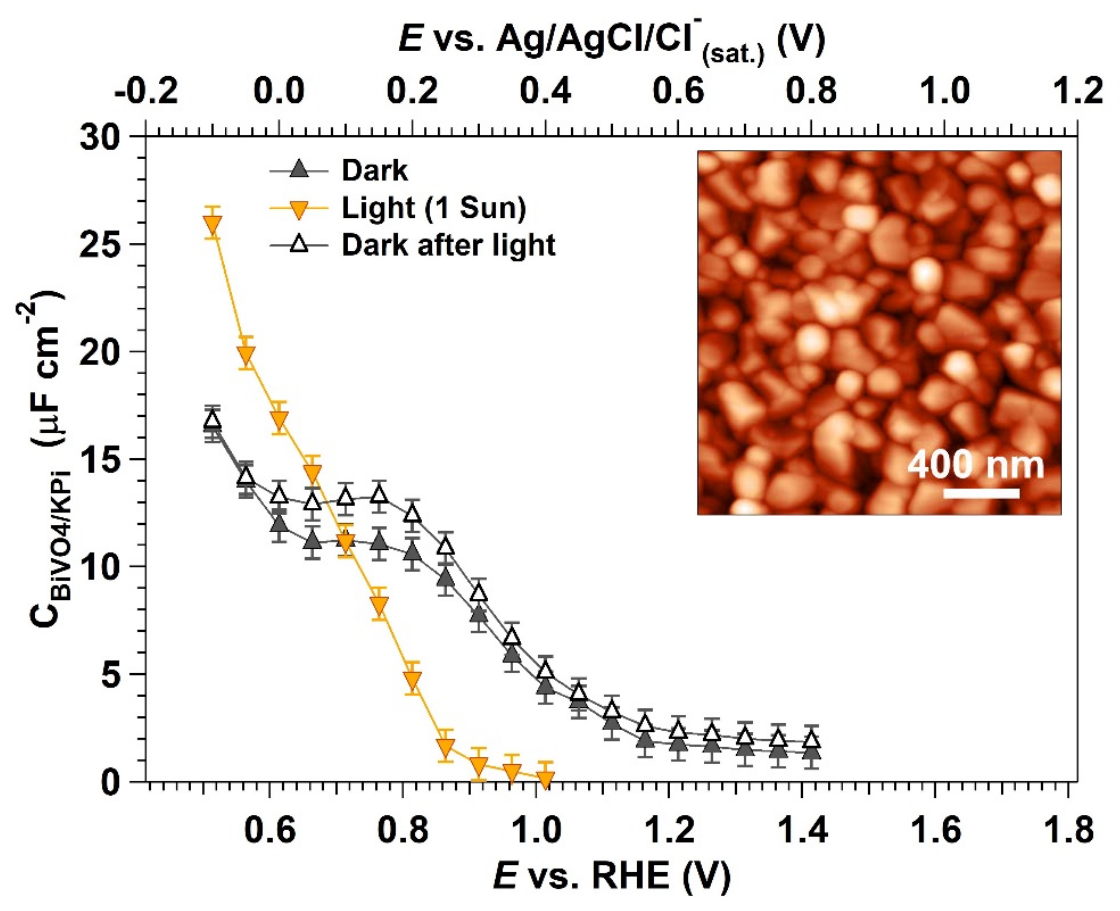

Figure 1. $\mathrm{BiVO}_{4} / \mathrm{KPi}$ electrolyte interface capacitance as a function of applied potential under dark and light conditions (1 sun, front illumination). The inset shows the surface morphology studied by atomic force microscopy (AFM).

recombination rate constant when depositing a cobalt phosphate catalyst layer on the $\mathrm{BiVO}_{4}$ surface. $^{20}$ The decrease in the recombination rate constant was attributed to surface state passivation by the deposited cobalt phosphate layer. The study by Zachäus et al. demonstrates that deposition of an overlayer can passivate surface recombination centers and lead to increased device performance. Our results, however, imply that surface state passivation can occur under illumination for the pristine $\mathrm{BiVO}_{4}$ surface which Zachäus et al. did not observe. This apparent discrepancy may simply be the result of the different light intensities used in the two studies. The intensity of light used in our study is about 25 times higher than that used by Zachäus et al. Since the surface state passivation observed here is associated with $\mathrm{BiVO}_{4}$ illumination we would expect to have significantly more passivation than Zachäus et al. due to the much higher light intensities used. Analogous to using overlayer deposition to passivate surface states as in the case of Zachäus et al., in the present study illumination of the $\mathrm{BiVO}_{4}$ may drive interfacial chemical reactions that effectively lead to the deposition of a passivating overlayer. ${ }^{38}$ Indeed, Trzésniewski et al. recently reported a light-soaking treatment that suppresses surface recombination in $\mathrm{BiVO}_{4}{ }^{39,}{ }^{40}$ In order to investigate light driven chemistry at the $\mathrm{BiVO}_{4} / \mathrm{KPi}$ electrolyte interface 
and to test this hypothesis we have conducted in situ AP-HAXPES measurements which allows for direct chemical interrogation of solid/liquid interfaces.

\section{In situ AP-HAXPES at the $\mathrm{BiVO}_{4} / \mathrm{KPi}$ interface}

In order to gain chemical information about the $\mathrm{BiVO}_{4} / \mathrm{KPi}$ aqueous electrolyte interface, we performed in situ AP-HAXPES using the "dip and pull” technique available at the Advanced Light Source at beamline 9.3.1 (Figure 2a). ${ }^{25,26,27, ~ 28, ~ 29, ~} 30$ We studied the chemical composition
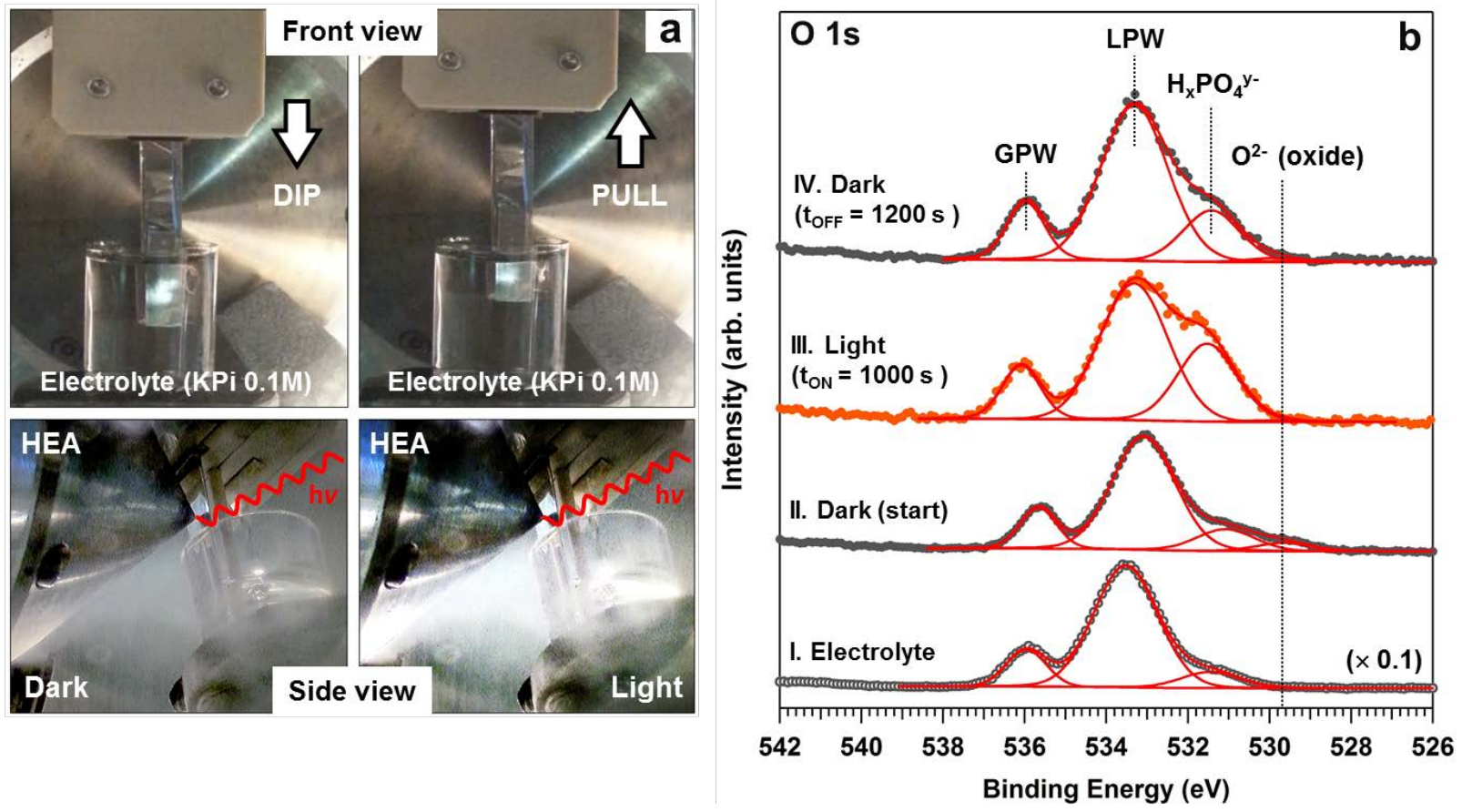

Figure 2. In situ AP-HAXPES experiments performed on a poly-crystalline $\mathrm{BiVO}_{4}$ /liquid electrolyte interface. Figure a shows digital photographs of the different phases of the experiment, such as the "dip and pull" procedure (top) and the AP-HAXPES measurements under dark and light conditions (bottom). HEA: hemispherical electron analyzer, note that in the top two photographs the view is from behind the sample towards the entrance aperture to the HEA; b: selected $\mathrm{O}$ 1s spectra and corresponding multipeak fitting procedure, I. KPi electrolyte only, II. the $\mathrm{BiVO}_{4} / \mathrm{KPi}$ electrolyte system initially in the dark, III. the $\mathrm{BiVO}_{4} / \mathrm{KPi}$ electrolyte system after $1000 \mathrm{~s}$ of illumination with a solar simulator, IV. The $\mathrm{BiVO}_{4} / \mathrm{KPi}$ electrolyte system $1200 \mathrm{~s}$ after returning to dark conditions.

of both the $\mathrm{BiVO}_{4}$ surface and KPi electrolyte as a function illumination and time. The measurements were conducted at the half-cell open circuit potential (OCP) to monitor chemical changes induced exclusively by illumination with the solar simulator. We monitored $\mathrm{O}$ 1s and $\mathrm{Bi}$ 4f photoelectron spectra as well as additional peaks related to the species in the electrolyte solution, namely the K 2p and P 2p spectra. Figure $2 \mathbf{b}$ shows selected $\mathrm{O}$ 1s spectra for the pure 
$\mathrm{KPi}$ electrolyte (Figure $\mathbf{2 b}, \mathbf{I}$ ), and the $\mathrm{BiVO}_{4} / \mathrm{KPi}$ electrolyte system in the dark and under illumination (Figure 2b, II, III, and IV). The O 1s photoelectron signal acquired for a thick electrolyte film (Figure 2b, I) can be de-convoluted into three different components: gas phase water (GPW) at about $536 \mathrm{eV}$, liquid phase water (LPW) at about $533.5 \mathrm{eV}$ and solvated phosphate ions $\left(\mathrm{HPO}_{4}{ }^{2-}\right.$ and $\mathrm{H}_{2} \mathrm{PO}_{4}{ }^{-}$, labelled as $\left.\mathrm{H}_{\mathrm{x}} \mathrm{PO}_{4}{ }^{\mathrm{y}}\right)$ ), at about $531.4 \mathrm{eV}$. The same deconvolution can be used to analyze the $\mathrm{O} 1$ s spectra acquired for the $\mathrm{BiVO}_{4} / \mathrm{KPi}$ interface, under dark and light conditions with the addition of a new component centered at a binding energy of about $529.7 \mathrm{eV}$. This peak arises from the $\mathrm{O}^{2-}$ anions of the $\mathrm{BiVO}_{4}$ (Figure 2b, II).

The thickness of the $\mathrm{KPi}$ aqueous electrolyte layer on the $\mathrm{BiVO}_{4}$ surface can be estimated using the ratio of the oxide to LPW O 1s peak intensities. We used Monte Carlo simulations of the photoelectron intensity implemented in the SESSA software package ${ }^{41}$ to model the oxide to LPW ratio. We can then compare the model calculation results to the ratios determined by the multipeak fitting procedure reported in Figure $\mathbf{2 b}$. The results of this analysis are reported in Figure S3. We used two different models: 1) a model with a flat $\mathrm{BiVO}_{4}$ surface and 2) a $\mathrm{BiVO}_{4}$ surface with a morphology more closely resembling the actual one where the model surface is based on the topography profiles reported in Figure S1. The two different surface models lead to similar results (Figure S3). Comparing the ratios found in the model to the experimentally determined ratios (0.056 in Figure 2b II, 0.012 in Figure 2b III and 0.019 in Figure 2b IV) shows that the electrolyte layer thickness was nearly constant throughout the experiment, with thicknesses ranging between 24 to $32 \mathrm{~nm}$.

Interestingly, when passing from dark to light conditions, the $\mathrm{H}_{\mathrm{x}} \mathrm{PO}_{4}{ }^{\mathrm{y}-}$ component drastically increases in intensity (Figure 2b, II and III) relative to the intensity of the LPW O 1s peak. Moreover, despite the significant increase of the phosphate $\mathrm{O}$ 1s signal upon illumination, it decreases once dark conditions are restored (Figure 2b, III and IV). We note that upon illumination the binding energies of the $\mathrm{O} 1 \mathrm{~s}$ peaks have shifted to slightly higher binding energies. The observed shifts are also reversible upon returning to dark conditions. These small shifts to higher binding energy of the $\mathrm{O} 1$ s spectra are consistent with a change in the open circuit potential to more negative values upon illumination (see below and refs. 23, 27, 28, 29, 30).

In addition to changes in the $\mathrm{O}$ 1s spectra, we also observe distinct changes in the APHAXPES signals arising from the ions in the electrolyte, as shown by the K $2 \mathrm{p}$ and $\mathrm{P} 2 \mathrm{p}$ core level spectra in Figure 3a and b, respectively. We observe a clear increase in the photoelectron 

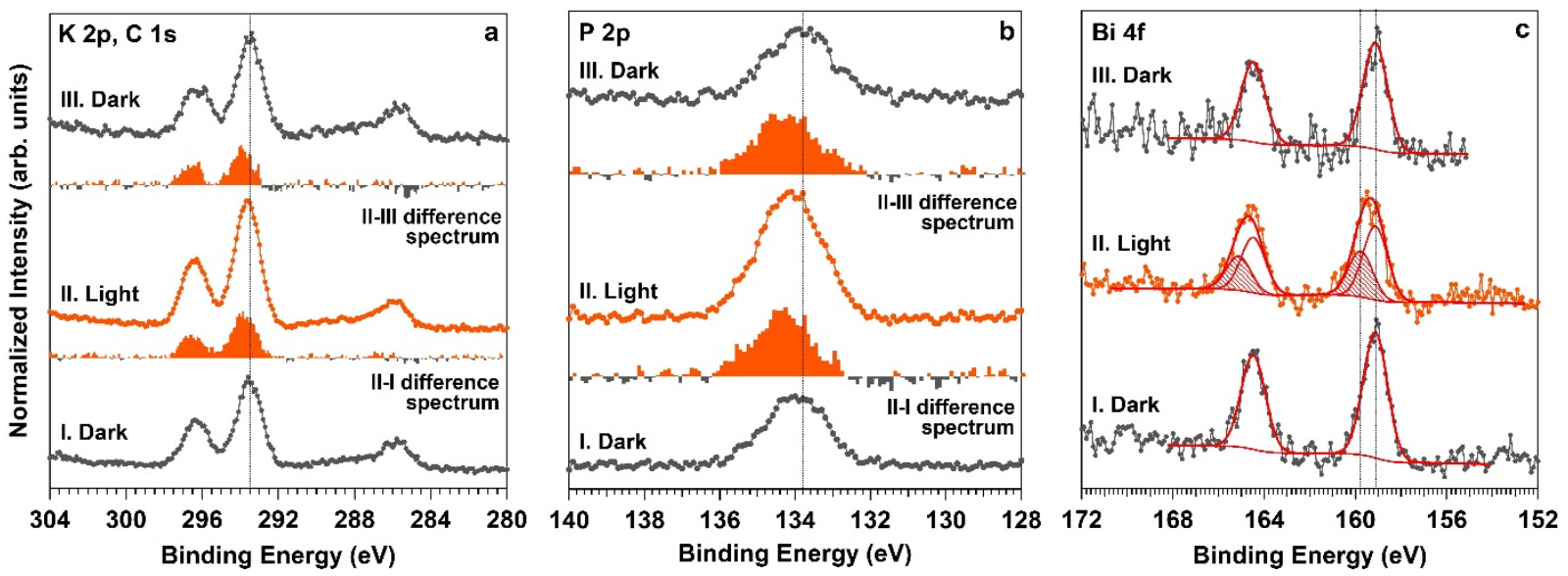

Figure 3. In situ AP-HAXPES experiments performed at room temperature and at $p \sim 17$ Torr on a poly-crystalline $\mathrm{BiVO}_{4} / \mathrm{KPi}$ aqueous electrolyte interface at the half-cell open circuit potential under illumination ( 0.92 sun) and dark conditions (hv=4.0 keV); a, b, and c: K 2p and C 1s, P 2p, and Bi $4 \mathrm{f}$ photoelectron spectra, respectively (I: spectra acquired in dark conditions at the beginning of the experiment; II: spectra acquired under light conditions ( 0.92 Sun) after 1000 s of illumination; III: spectra acquired $1200 \mathrm{~s}$ after returning to dark conditions). In figure a and b, II - I and II - III correspond to the difference spectra obtained by subtracting the spectra taken in the dark (I and III) from spectrum II acquired under light conditions.

intensity from both $\mathrm{K}^{+}$and $\mathrm{P}$ in the phosphate groups $\left(\mathrm{H}_{\mathrm{X}} \mathrm{PO}_{4}{ }^{\mathrm{y}-}\right)$ when passing from dark to light conditions. This is highlighted by the difference spectra in Figure 3a and $\mathbf{3 b}$. Similar to what is described above for the $\mathrm{O}$ 1s spectra, the increase in the signal intensity from the ions in the electrolyte upon illumination is reversible when restoring dark conditions.

Figure 3c shows $\mathrm{Bi} 4 \mathrm{f}$ photoelectron spectra for both dark and light conditions. Upon illumination the Bi 4f peak broadens to higher binding energy (Figure 3c, II). The addition of a second component at $+0.7 \mathrm{eV}$ higher binding energy from the main $\mathrm{Bi} 4 \mathrm{f}$ spectral feature $\left(\mathrm{Bi}^{3+}\right.$, $\mathrm{BE}=159.1 \mathrm{eV}$ ) allows quantification of the broadening. We note that the carbon contamination (BE $285 \mathrm{eV}$ ) present is not affected when passing from dark to light conditions.

Finally, it was not possible to acquire the V 2p photoelectron peak under in situ conditions, due to the low intensity of the photoelectron signal. Figure S4 reports the Bi 4f, V 2p and O 1s photoelectron signals acquired before the dip and pull procedure at the $\mathrm{BiVO}_{4} /$ water vapor interface, at fully hydrated conditions ( $\mathrm{p}_{\text {water }} \sim 18$ Torr at room temperature) where the V 2p is clearly present.

\section{Discussion}

In this section, we rationalize the AP-HAXPES results reported above. First, we will discuss chemical changes of the $\mathrm{BiVO}_{4}$ induced by light, through an analysis of the broadening of the $\mathrm{Bi}$ 
4f core level spectra. Secondly, we will analyze the time evolution of the $\mathrm{H}_{\mathrm{x}} \mathrm{PO}_{4}{ }^{\mathrm{y}-}$ to $\mathrm{LPW}$ ratio to understand how the redistribution of ions in the thin electrolyte film is linked to the chemical modifications at the interface. Lastly, we will present a model that summarizes our results.

The in situ AP-HAXPES investigation of the $\mathrm{BiVO}_{4} / \mathrm{KPi}$ aqueous electrolyte interface at the half-cell OCP shows that $\mathrm{Bi}$ 4f photoelectron peak undergoes a spectral broadening under illumination. This broadening was accounted for by adding a second component (centered at a $4 \mathrm{f}_{7 / 2} \mathrm{BE}$ of $159.8 \pm 0.1 \mathrm{eV}$ ) in addition to the main $\mathrm{Bi}^{3+}$ contribution (centered at a $4 \mathrm{f}_{7 / 2} \mathrm{BE}$ of $159.1 \pm 0.1 \mathrm{eV})$. Previous work has reported a $\mathrm{Bi} 4 \mathrm{f}_{7 / 2} \mathrm{BE}$ of $159.8 \pm 0.1 \mathrm{eV}$ for bismuth phosphate. $^{42,43,44,45}$ We note that a broadening of $0.7 \mathrm{eV}$ is too large to be a result of band flattening alone. Previous studies have indicated an upward band bending of $\sim 0.3 \mathrm{eV}$ at the $\mathrm{BiVO}_{4} / \mathrm{KPi}$ aqueous electrolyte interface suggesting that the largest amount of band flattening expected upon illumination is $\sim 0.3 \mathrm{eV}{ }^{16}$ In addition, core-level peaks should shift to higher binding energies and narrow with band flattening as opposed to the broadening observed here. Therefore, we assign the broadening of the $\mathrm{Bi} 4 \mathrm{f}$ peak under illumination to the formation of bismuth phosphate $\left(\mathrm{BiPO}_{4}\right)$. Note that we cannot quantitatively determine the number of phosphate groups per $\mathrm{Bi}$ atom using the $\mathrm{P} 2 \mathrm{p}$ or $\mathrm{O}$ 1s core-level intensities due to the large photoelectron signal intensity of the phosphate anions from the liquid electrolyte. Therefore, further experiments are required to determine the precise stoichiometry of the bismuth phosphate layer. The $\mathrm{Bi} 4 \mathrm{f}$ intensity ratio between the $\mathrm{BiPO}_{4}$ and the $\mathrm{Bi}^{3+}$ components for the $\mathrm{BiVO}_{4} / \mathrm{KPi}$ aqueous electrolyte system under illumination is equal to 0.62 ; or the $\mathrm{BiPO}_{4}$ signal is $0.62 /(0.62+1)=0.38$ of the total Bi $4 \mathrm{f}$ signal (see Figures $3 \mathbf{b}$ ). We used the SESSA software package $^{41}$ to estimate the thickness of bismuth phosphate that is necessary to account for this fraction of the total $\mathrm{Bi} 4 \mathrm{f}$ signal. Our estimate includes the following assumptions; 1) that the density of bismuth in the bismuth phosphate layer is the same as in $\mathrm{BiVO}_{4}, 2$ ) that the bismuth phosphate layer is flat, and (3) that the bismuth phosphate layer covers the underlying $\mathrm{BiVO}_{4}$ homogeneously. Under these assumptions we estimate that the bismuth phosphate layer formed under illumination is $2.3 \mathrm{~nm}$ thick. This thickness is equivalent to $\sim 8$ layers of $\mathrm{BiVO}_{4}$ assuming a $\mathrm{BiVO}_{4}$ layer thickness of $2.92 \AA$, which is $1 / 4$ the lattice constant in the [010] direction of crystalline $\mathrm{BiVO}_{4}{ }^{19,}{ }^{24} \mathrm{~A}$ possible mechanism for the formation of bismuth phosphate is photocorrosion of $\mathrm{BiVO}_{4}{ }^{18}$ combined with precipitation of bismuth phosphate from solution. If this is the case the growth bismuth phosphate will be self-limiting.

Bismuth phosphate is an $n$-type semiconductor with a wide band gap of $3.85 \mathrm{eV}^{45,46}$ and 
possesses a large dipole due to the highly negative, polarizable, $\mathrm{PO}_{4}{ }^{3-}$ units. $\mathrm{BiPO}_{4} / \mathrm{BiVO}_{4}$ composites have shown enhanced visible-light photocatalytic activity for methylene blue degradation compared to either $\mathrm{BiVO}_{4}$ or $\mathrm{BiPO}_{4}$ alone. ${ }^{45}$, 46 This has been attributed to the $\mathrm{BiPO}_{4} / \mathrm{BiVO}_{4}$ junction hindering electron-hole recombination, i.e. passivation of recombination centers upon $\mathrm{BiPO}_{4}$ deposition. The formation of bismuth phosphate observed here may have a
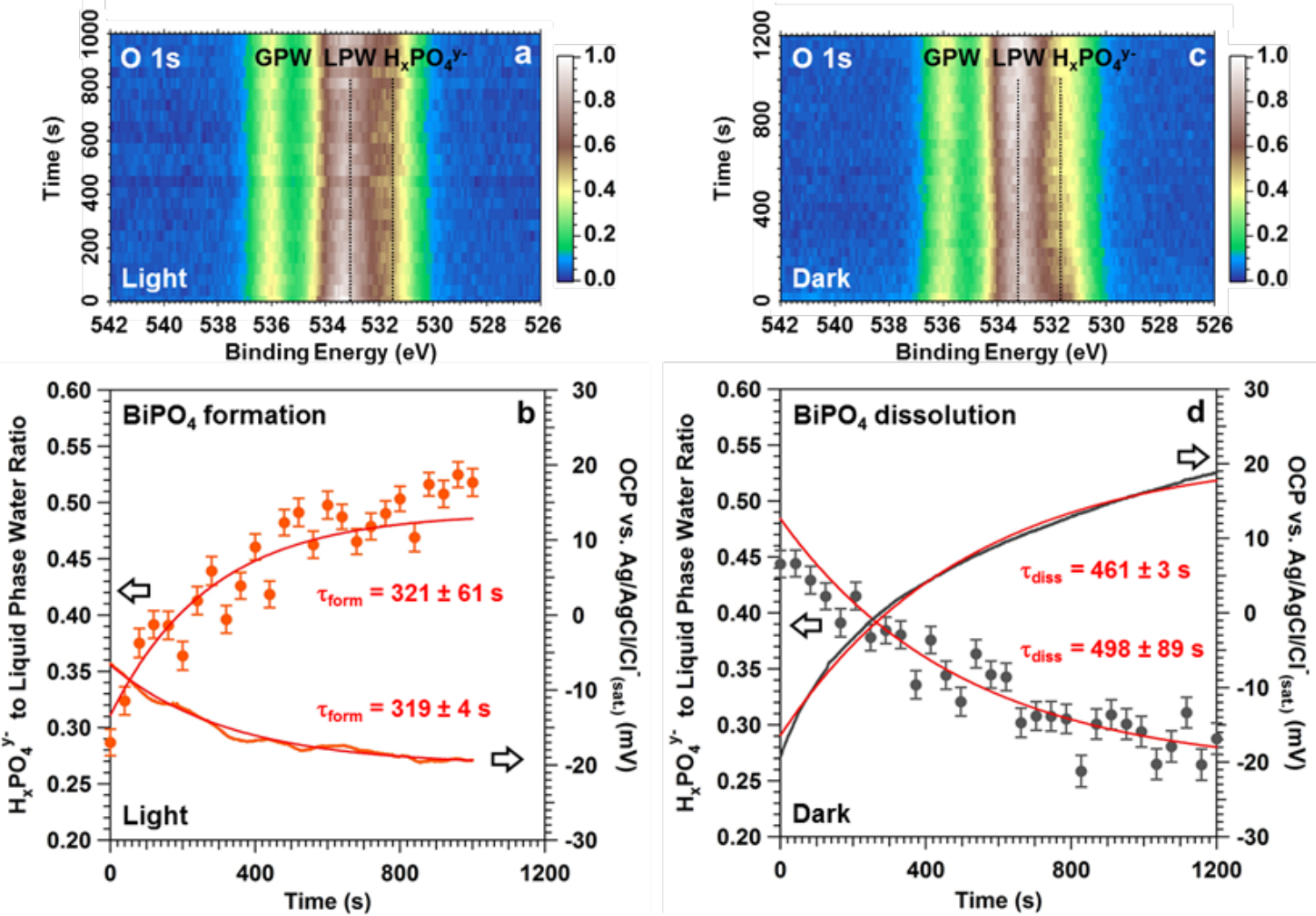

Figure 4. Time evolution of the $\mathrm{O} 1 \mathrm{~s}$ spectra at the half-cell open circuit potential (OCP) under illumination (a, 0.92 sun) and after returning to dark conditions (c) (one spectrum every $40 \mathrm{~s}$ ). Figures b and $\mathbf{d}$ show the phosphate ion $\left(\mathrm{H}_{\mathrm{x}} \mathrm{PO}_{4}{ }^{\mathrm{y}-}\right)$ to liquid phase water (LPW) $\mathrm{O}$ 1s peak intensity ratio as a function of time found by integrating the areas under the peaks in the individual spectra in a and c using the multi-peak fitting procedure reported in Figure $2 \mathrm{~b}$. Also included in Figures $\mathbf{b}$ and $\mathbf{d}$ is the OCP as function of time. Corresponding time constants found by fitting to single exponential functions are provided in the figures.

beneficial effect on the photoelectrochemical properties of $\mathrm{BiVO}_{4}$ photoanodes in $\mathrm{KPi}$ solution similar to the passivating effects of cobalt layer deposition. ${ }^{20}$ This is suggested by the loss of the surface state feature observed in the capacitance versus applied potential plots upon illumination (Figure 1). However, since the bismuth phosphate layer may be formed via initial photocorrosion of $\mathrm{BiVO}_{4}$ followed by $\mathrm{BiPO}_{4}$ precipitation, controlling both the extent of photocorrosion as well as the thickness of the bismuth phosphate layer would be necessary to fully realize its potential 
beneficial effects.

We have investigated the time evolution of the light induced changes in the thin electrolyte film by plotting the $\mathrm{H}_{\mathrm{x}} \mathrm{PO}_{4}{ }^{\mathrm{y}-}$ to LPW O 1 s signal ratio as a function of time. The time-dependent $\mathrm{O}$ 1s spectra acquisition reported in Figure 4a and $\mathbf{4 c}$, show the decay of the low binding energy tail as a function of time when passing from light to dark conditions. We have extracted time constants by fitting the ratio to a single exponential function, which assumes first order kinetics. This is shown in Figures $\mathbf{4 b}$ and $\mathbf{4 d}$. For comparison we have also included in Figures $\mathbf{4 b}$ and $\mathbf{4 d}$ the time evolution of the half-cell OCP during the same time period with a similar single exponential fit. The time evolution for both the $\mathrm{H}_{\mathrm{x}} \mathrm{PO}_{4}{ }^{\mathrm{y}-}$ to LPW O 1 s signal ratio and the OCP match quite well and are fit with similar time constants suggesting that the changes in the two measured quantities are related to the same process. The change in the OCP indicates that upon illumination the surface becomes more negatively charged. This implies that the process that leads to the observed changes in the $\mathrm{O} 1 \mathrm{~s}_{\mathrm{x}} \mathrm{PO}_{4}{ }^{\mathrm{y}-}$ to LPW signal ratio results in a more negatively charged surface. The extracted time constants are summarized in Table $\mathbf{1}$ showing that

Table 1. Change in $\mathrm{H}_{\mathrm{x}} \mathrm{PO}_{4}^{\mathrm{y}-}$ to LPW O 1 s signal intensity ratio and OCP time constants determined from the in situ AP-HAXPES and photoelectrochemical data.

\section{LIGHT}

DARK

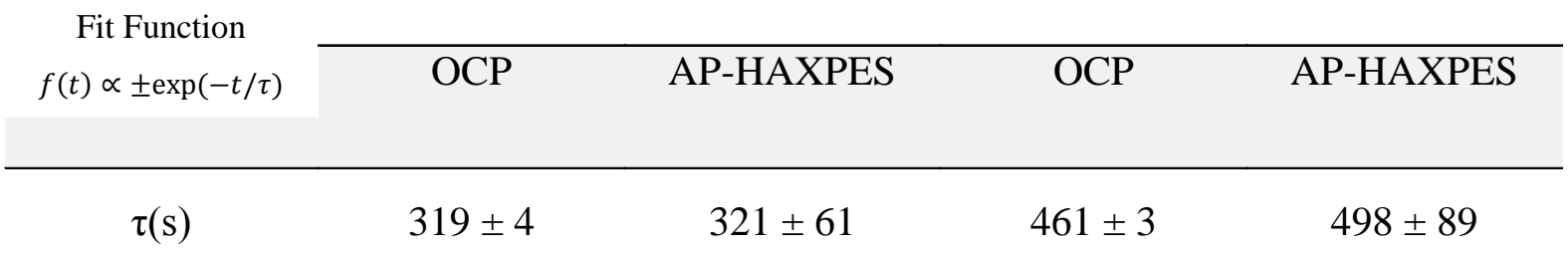

the time scale for the light induced changes at the interface is on the order of 100 s of seconds for both the forward and reverse processes. This time scale allows us to eliminate some possibilities for the observed changes in the $\mathrm{H}_{\mathrm{x}} \mathrm{PO}_{4}{ }^{\mathrm{y}-}$ to LPW O 1 s signal ratio.

First, we note that the $\mathrm{H}_{\mathrm{x}} \mathrm{PO}_{4}{ }^{\mathrm{y}-}$ to LPW O 1s signal ratio change can arise from two processes: 1) an increase in the $\mathrm{H}_{\mathrm{x}} \mathrm{PO}_{4}{ }^{\mathrm{y}-}$ concentration in the thin electrolyte film upon illumination, or 2) a change in the distribution of $\mathrm{H}_{\mathrm{x}} \mathrm{PO}_{4}{ }^{\mathrm{y}-}$ anions within the thin electrolyte film that shifts their average position closer to the electrolyte/vapor interface (XPS is always more sensitive to species closer to the surface since their photoelectrons are attenuated less ${ }^{47}$ ). An increase in the concentration of phosphate ions in the $\mathrm{BiVO}_{4} / \mathrm{KPi}$ system may be the result of $\mathrm{BiPO}_{4}$ formation. 
This is because, $\mathrm{BiPO}_{4}$ formation may lead to a depletion of the phosphate ions in the thin aqueous electrolyte film and produce a phosphate ion concentration gradient that extends from the electrolyte in the beaker to the measurement position (see Figure 2a). This concentration gradient could provide a driving force for phosphate anions to diffuse from the beaker to the APHAXPES measurement position in order to re-establish the initial $\mathrm{H}_{\mathrm{x}} \mathrm{PO}_{4}{ }^{\mathrm{y}-}$ anion concentration in the thin electrolyte film. The phosphate signal would then increase since the signal would be a sum of the phosphate in the $\mathrm{BiPO}_{4}$ layer plus the $\mathrm{H}_{\mathrm{X}} \mathrm{PO}_{4}{ }^{\mathrm{y}-}$ anions in the thin electrolyte film that have re-established their initial, dark conditions concentration. We can estimate the timescale for such a diffusion process by calculating the amount of phosphate ions in the bismuth phosphate film (and therefore the amount that has been depleted from the thin electrolyte film, $3.11 \times 10^{-9}$ mol of phosphate anions), using the known distance from the beaker to the AP-HAXPES measurement position $(1 \mathrm{~cm})$ and the diffusion constant for phosphate anions $\left(\mathrm{D}=7.910^{-6} \mathrm{~cm}^{2} \mathrm{~s}^{-}\right.$ $\left.{ }^{1}\right)^{48}$ in conjunction with Fick's first law of diffusion. Note that the cross-section of the thin electrolyte film is small, about $0.7 \mathrm{~cm} \times 30 \times 10^{-7} \mathrm{~cm}=2.1 \times 10^{-6} \mathrm{~cm}^{2}$. The results of such a calculation lead to timescales on the order of $10^{5} \mathrm{~s}$ which is orders of magnitude longer than the 100s of seconds we observe. Therefore, it is highly unlikely that diffusion of phosphate anions from the beaker to the AP-HAXPES measurement position is responsible for the increase in the $\mathrm{H}_{\mathrm{x}} \mathrm{PO}_{4}{ }^{\mathrm{y}-}$ to LPW O 1 s signal ratio upon illumination.

Further, a timescale of 100s of seconds is far too long for the observed changes in the $\mathrm{H}_{\mathrm{x}} \mathrm{PO}_{4}{ }^{\mathrm{y}-}$ to LPW O 1s signal ratio to be due to the redistribution of the ions in the electrolyte driven by a change in the charge on the $\mathrm{BiVO}_{4}$ surface alone. For an ion to move $30 \mathrm{~nm}$, the full thickness of the electrolyte film, under the influence of a change in field, as estimated by the change in OCP, a timescale on the order of microseconds should be observed. ${ }^{49}$ In addition, the timescale for changes in the surface photovoltage can vary extensively depending on the material and surface but is generally much shorter than 100s of seconds (for example in reference ${ }^{50}$ timescales of 6.6 $\mu$ s and $1.2 \mathrm{~ms}$ were observed for $\mathrm{Si}(111)$ and $\mathrm{ZnO}(10 \overline{10})$, respectively). Instead the observed time evolution is likely due to a chemical transformation occurring at the interface and is quite likely associated with bismuth phosphate formation. The build-up of bismuth phosphate on the $\mathrm{BiVO}_{4}$ surface leads to an increase in the negative charge of the surface (either by suppression of charge recombination and/or surface polarization due to the large dipole of $\mathrm{BiPO}_{4}$ ) and as a result leads to the redistribution of ions in the thin electrolyte film. The ions in the thin electrolyte film react effectively instantaneously to a change in charge of the surface (see above), the timescale 
for which depends on the timescale for bismuth phosphate formation. The reversibility of the light-driven process is clear once the dark conditions are restored (Figure 4d). The half-cell OCP shifts toward positive values whereas the $\mathrm{H}_{\mathrm{X}} \mathrm{PO}_{4}{ }^{\mathrm{y}-}$ to LPW O 1 s signal ratio decreases.

Concomitant with the formation of bismuth phosphate, an increase in both the anion (phosphate) and cation $\left(\mathrm{K}^{+}\right)$AP-HAXPES signals is observed when going from dark to light conditions at the half-cell OCP (see Figures $2 \mathbf{b}$ (O 1s signal from the phosphate anions), 3a and 3c (K 2p and P 2p signals, respectively)). An increase in the $\mathrm{K}^{+}$signal upon illumination may seem counter-intuitive since the surface becomes more negatively charged upon illumination. In a point charge model of the electrolyte the $\mathrm{K}^{+}$ions should then be more attracted to the surface and their AP-HAXPES signal should decrease. However, previous studies have shown that phosphate salts bearing small cations (such as $\mathrm{K}^{+}$) lie at the extreme left of the Hofmeister series, ${ }^{51}$ have high hydration numbers (typically exceeding 10$)^{52}$ and strong ion-pairing when dissolved in water. ${ }^{52}$ This means that despite the high dielectric constant of water, phosphate salts such as $\mathrm{KH}_{2} \mathrm{PO}_{4}$ and $\mathrm{K}_{2} \mathrm{HPO}_{4}$ are not completely dissociated in aqueous solution, but hydrated with ion-

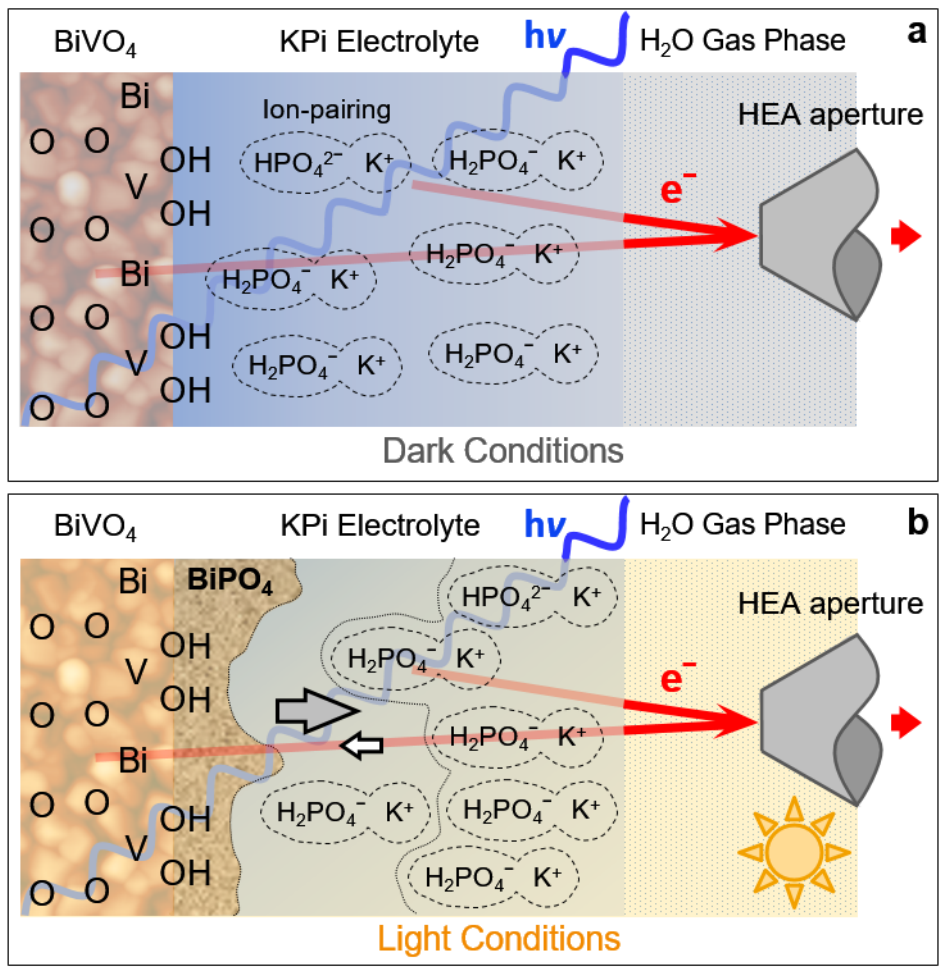

Figure 5. Schematic rationalizing the experimental observations, dark conditions (a) and under illumination (b). Under illumination bismuth phosphate forms on the surface which is associated with the build-up of negative charge and the redistribution of ions in the $0.1 \mathrm{M} \mathrm{KPi}$ electrolyte away from the $\mathrm{BiVO}_{4}$ surface. 
paired configurations. ${ }^{52}$ This may explain the increase in $\mathrm{K}^{+}$signal. Essentially, phosphate groups bind and drag $\mathrm{K}^{+}$cations as they shift toward the electrolyte/gas interface under light conditions.

The proposed model rationalizing our experimental observations is summarized in Figures 5a and $\mathbf{5 b}$. Under visible light absorption, electrochemical capacitance measurements indicate the extinction of the surface state observed in dark (surface passivation). This is likely due to a $\mathrm{BiPO}_{4}$ passivation layer formed via photocorrosion followed by $\mathrm{BiPO}_{4}$ precipitation. As the $\mathrm{BiPO}_{4}$ layer forms, the surface becomes more negatively charged either due to a reduction in charge carrier recombination and/or a large surface dipole. This is observed by the lowering of the half-cell OCP (which passes, at steady state conditions, from $+30 \mathrm{mV}$ in dark to $-25 \mathrm{mV}$ under illumination). The timescale for this process is in the 100s of seconds. The increase in surface negative charge causes a stronger repulsive interaction between the negatively-charged phosphate anions and the surface and shifts the solvated phosphate ion distribution further away from the surface and closer to the electrolyte/gas interface (Figure 5b, light conditions), thereby increasing their AP-HAXPES signal. Due to strong ion pairing between the potassium cations and the phosphate anions the potassium ion AP-HAXPES signal also increases.

\section{Conclusions}

Combining AP-HAXPES and photoelectrochemistry techniques we have shown that the $\mathrm{BiVO}_{4} / \mathrm{KPi}$ electrolyte interface undergoes a chemical modification upon absorption of visible light at the half-cell open circuit potential (OCP). Under such conditions, photocorrosion induced by illumination triggers the formation of bismuth phosphate on the surface of the $\mathrm{BiVO}_{4}$ photoanode. This leads to surface passivation and the quenching of the surface state observed on undoped $\mathrm{BiVO}_{4}$ under dark conditions. Moreover, the formation of bismuth phosphate is correlated with the build-up of negative charge on the surface which, in turn, causes a redistribution of ions in the thin KPi electrolyte film. We find that these changes are reversible upon restoring dark conditions. This work highlights the importance of using in situ methods to understand how working conditions play a crucial role in modulating the properties of photoanodes. For instance, the formation of a $\mathrm{BiPO}_{4}$ layer forms a junction between a low bandgap oxide $\left(\mathrm{BiVO}_{4}, 2.4 \mathrm{eV}\right)$ and a higher band-gap material $\left(\mathrm{BiPO}_{4}, 3.85 \mathrm{eV}\right)^{45}$ and will modify the local density of states of the photoanode surface which in turn will influence device performance. We have shown that the formation of a $\mathrm{BiPO}_{4}$ layer may lead to surface passivation and a recovery of the band edge pinning and a decrease in the charge recombination rate, 
providing a rational for previous results reported in the literature. ${ }^{45,46}$ In the present study, such processes are a result of a specific semiconductor/electrolyte combination and suggest that the choice of supporting electrolyte may play a significant role in photoelectrochemical device performance.

\section{Supporting Information}

Atomic Force Microscopy image of the $\mathrm{BiVO}_{4}$ thin film, cyclic voltammetry and capacitive current scans under dark and light conditions, simulated photoelectron intensity attenuation through water layers of varying thickness, $\mathrm{O}$ 1s, $\mathrm{V} 2 \mathrm{p}$ and $\mathrm{Bi}$ 4f spectra of the $\mathrm{BiVO}_{4}$ film in water vapor pressures of 18 Torr.

\section{Acknowledgements}

This research was conducted, in part, at the Advanced Light Source of the Lawrence Berkeley National Laboratory, a DOE Office of Science User Facility under contract no. DEAC02-05CH11231. This work was supported by the German Federal Ministry of Education and Research (BMBF project “Grundlagen elektrochemischer Phasengrenzen, GEP). 


\section{References}

(1) Lewis, N. S.; Nocera, D. G. Powering the Planet: Chemical Challenges in Solar Energy Utilization. Proc. Natl. Acad. Sci. 2006, 103, 15729-15735.

(2) Gust, D.; Moore, T. A.; Moore, A. L. Mimicking Photosynthetic Solar Energy Transduction. Acc. Chem. Res. 2001, 34, 40-48.

(3) Chu, S.; Cui, Y.; Liu, N. The Path towards Sustainable Energy. Nat. Mater. 2017, 16, 16-22.

(4) Barton, E. E.; Rampulla, D. M.; Bocarsly, A. B. Selective Solar-Driven Reduction of $\mathrm{CO}_{2}$ to Methanol using a Catalyzed p-GaP based Photoelectrochemical Cell. J. Am. Chem. Soc. 2008, 130, 6342-6344.

(5) Morris, A. J.; Meyer, G. J.; Fujita, E. Molecular Approaches to the Photocatalytic Reduction of Carbon Dioxide for Solar Fuels. Acc. Chem. Res., 2009, 42, 1983-1994.

(6) Centi, G.; Perathoner, S. Opportunities and Prospects in the Chemical Recycling of Carbon Dioxide to Fuels. Catalysis Today, 2009, 148, 191-205.

(7) Sivula, K.; van de Krol, R. Semiconducting Materials for Photoelectrochemical Energy Conversion. Nature Reviews Materials 2016, 1, 15010.

(8) Walter, M. G.; Warren, E. L.; McKone, J. R.; Boettcher, S. W.; Mi, Q.; Santori, E. A.; Lewis, N. S. Solar Water Splitting Cells. Chem. Rev. 2010, 110, 6446-6473.

(9) Sun, J.; Zhong, D. K.; Gamelin, D. R. Composite Photoanodes for Photoelectrochemical Solar Water Splitting. Energy Environ. Sci. 2010, 3, 1252-1261.

(10) Tachibana, Y.; Vayssieres, L.; Durrant, J. R. Artificial Photosynthesis for Solar Water-Splitting. Nat. Photon. 2012, 6, 511-518.

(11) Carraro, F.; Calvillo, L.; Cattelan, M.; Favaro, M.; Righetto, M.; Nappini, S.; Píš, I.; Celorrio, V.; Fermín, D. J.; Martucci, A., Et al. Fast One-Pot Synthesis of $\mathrm{MoS}_{2} /$ Crumpled Graphene p-n Nanonjunctions for Enhanced Photoelectrochemical Hydrogen Production. ACS Appl. Mater. Interfaces 2015, 7, 25685-25692.

(12) Ampelli, C.; Tavella, F.; Genovese, C.; Perathoner, S.; Favaro, M.; Centi, G. Analysis of the Factors Controlling Performances of Au-Modified $\mathrm{TiO}_{2}$ Nanotube Array Based Photoanode in PhotoElectrocatalytic (PECa) Cells. J. Energy Chem. 2017, 26, 284-294.

(13) Ager, J. W. Photoelectrochemical Approach for Water Splitting. Solar to Chemical Energy Conversion 2016, 32, 249-260.

(14) Yang, J.; Cooper, J. K.; Toma, F. M.; Walczak, K. A.; Favaro, M.; Beeman, J. W.; Hess, L. H.; Wang, C.; Zhu, C.; Gul, S., et al. A Multifunctional Biphasic Water Splitting Catalyst Tailored for Integration with High-Performance Semiconductor Photoanodes. Nat. Mater. 2017, 16, 335-341.

(15) Park, Y.; McDonald, K. J.; Choi, K.-S. Progress in Bismuth Vanadate Photoanodes for Use in Solar Water Oxidation. Chem. Soc. Rev. 2013, 42, 2321-2337.

(16) Abdi, F. F.; Han, L.; Smets, A. H. M.; Zeman, M.; Dam, B.; van de Krol, R. Efficient Solar Water Splitting by Enhanced Charge Separation in a Bismuth Vanadate-Silicon Tandem Photoelectrode. Nat. Commun. 2013, 4, 2195.

(17) Huang, Z.-F.; Pan, L.; Zou, J.-J.; Zhang, X.; Wang, L. Nanostructured Bismuth Vanadate-Based Materials for Solar-Energy-Driven Water Oxidation: a Review on Recent Progress. Nanoscale 2014, 6, 14044-14063. 
(18) Toma, F. M.; Cooper, J. K.; Kunzelmann, V.; McDowell, M. T.; Yu, J.; Larson, D. M.; Borys, N. J.; Abelyan, C.; Beeman, J. W.; Yu, K. M., Et al. Mechanistic Insights into Chemical and Photochemical Transformations of Bismuth Vanadate Photoanodes. Nat. Commun. 2016, 7, 12012.

(19) Sharp, I. D.; Cooper, J. K.; Toma, F. M.; Buonsanti, R. Bismuth Vanadate as a Platform for Accelerating Discovery and Development of Complex Transition-Metal Oxide Photoanodes. ACS Energy Lett., 2017, 2, 139-150.

(20) Zachäus, C.; Abdi, F. F.; Peter, L. M.; van de Krol, R. Photocurrent of $\mathrm{BiVO}_{4}$ is Limited by Surface Recombination, not Surface Catalysis. Chem. Sci. 2017, 8, 3712-3719.

(21) Ma, Y.; Pendlebury, S. R.; Reynal, A.; Le Formal, F; Durrant, J. R. Dynamics of Photogenerated Holes in Undoped $\mathrm{BiVO}_{4}$ Photoanodes for Solar Water Oxidation. Chem. Sci. 2014, 5, 2964-2973.

(22) Bard, A. J.; Bocarsly, A. B.; Fan, F.-R. F.; Walton, E. G.; Wrighton, M. S. The Concept of Fermi Level Pinning at Semiconductor/Liquid Junctions. Consequences for Energy Conversion Efficiency and Selection of Useful Solution Redox Couples in Solar Devices. J. Am. Chem. Soc. 1980, 102, 3671-3677.

(23) Lewerenz, H.-J.; Lichterman, M. F.; Richter, M. H.; Crumlin, E. J.; Hu, S.; Axnanda, S.; Favaro, M.; Drisdell, W.; Hussain, Z.; Brunschwig, B. S., Et al. Operando Analyses of Solar Fuels Light Absorbers and Catalysts. Electrochim. Acta 2016, 211, 711-719.

(24) Starr, D. E., Favaro, M.; Abdi, F.-F.; Bluhm, H.; Crumlin, E. J.; van de Krol, R. Combined Soft and Hard X-ray Ambient Pressure Photoelectron Spectroscopy Studies of Semiconductor/Electrolyte Interfaces. J. Elect. Spectrosc. Relat. Phenom. 2017, 10.1016/j.elspec.2017.05.003.

(25) Axnanda, S.; Crumlin, E. J., Mao, B.; Rani, S.; Chang, R.; Karlsson, P. G.; Edwards, M. O. M.; Lundqvist, M.; Moberg, R.; Ross, P. N.; Hussain, Z.; Liu, Z. Using 'tender' X-ray Ambient Pressure Xray Photoelectron Spectroscopy as a Direct Probe of Solid-Liquid Interface. Sci. Rep. 2015, 5, 9788.

(26) Karslioglu, O.; Nemšák, S.; Zegkinoglou, I.; Shavorskiy, A.; Hartl, M.; Salmassi, F.; Gullikson, E. M.; Ng, M. L.; Rameshan, Ch.; Rude, B.; Et al. Aqueous Solution/Metal Interfaces Investigated in Operando by Photoelectron Spectroscopy. Faraday Discuss. 2015 180, 35-53.

(27) Lichterman, M. F.; Hu, S.; Richter, M. H.; Crumlin, E. J.; Axnanda, S.; Favaro, M.; Drisdell, W. S.; Hussain, Z.; Mayer, T.; Brunschwig, B. S. Et al. Direct Observation of the Energetics at a Semiconductor/Liquid Junction by Operando X-ray Photoelectron Spectroscopy. Energy Environ. Sci., 2015, 8, 2409-2416.

(28) Favaro, M.; Jeong, B.; Ross, P. N.; Yano, J.; Hussain, Z.; Liu, Z.; Crumlin, E. J. Unravelling the Electrochemical Double Layer by Direct Probing of the Solid/Liquid Interface. Nat. Commun. 2016, 7, 12695.

(29) Favaro, M.; Drisdell, W. S.; Marcus, M. A.; Gregoire, J. M.; Crumlin, E. J.; Haber, J. A.; Yano, J. An Operando Investigation of (Ni-Fe-Co-Ce) $\mathrm{O}_{\mathrm{x}}$ System as Highly Efficient Electrocatalyst for Oxygen Evolution Reaction. ACS Catalysis 2017, 7, 1248-1258.

(30) Favaro, M.; Valero-Vidal, C.; Eichhorn, J.; Toma, F. M.; Ross, P. N.; Yano, J.; Liu, Z.; Crumlin, E. J. Elucidating the Alkaline Oxygen Evolution Reaction Mechanism on Platinum. J. Mater. Chem. A 2017, 5, 11634-11643.

(31) Favaro, M.; Yang, J.; Nappini, S.; Magnano, E.; Toma, F. M.; Crumlin, E. J.; Yano, J.; Sharp, I. D. Understanding the Oxygen Evolution Reaction Mechanism on $\mathrm{CoO}_{\mathrm{x}}$ Using Operando Ambient-Pressure X-ray Photoelectron Spectroscopy. J. Am. Chem. Soc. 2017, 139, 8960-8970.

(32) Abdi, F. F.; van de Krol, R. Nature and Light Dependence of Bulk Recombination in Co-PiCatalyzed $\mathrm{BiVO}_{4}$ Photoanodes. J. Phys. Chem. C 2012, 116, 9398-9404. 
(33) Velasco-Velez, J.-J.; Wu, C. H.; Pascal, T. A.; Wan, L. F.; Guo, J.; Prendergast, D.; Salmeron, M. The Structure of Interfacial Water on Gold Electrodes Studied by X-ray Absorption Spectroscopy. Science 2014, 346, 831-834.

(34) Tougaard; S. Practical Algorithm for Background Subtraction. Surf. Sci. 1989, 216, 343-360.

(35) Evans, S. Curve Synthesis and Optimization Procedures for X-ray Photoelectron Spectroscopy. Surf. Interface Anal. 1991, 17, 85-93.

(36) Muñoz-Flores, J.; Herrera-Gomez, A. Resolving Overlapping Peaks in ARXPS Data: the Effect of Noise and Fitting Method. J. Electron Spectrosc. Relat. Phenom. 2012, 184, 533-541.

(37) Gomes, W. P.; Vanmaekelbergh, D. Impedance Spectroscopy at Semiconductor Electrodes: Review and Recent Developments. Electrochim. Acta 1996, 41, 967-973.

(38) Hagfeldt, A.; Grätzel, M. Light-Induced Redox Reactions in Nanocrystalline Systems. Chem. Rev. 1995, 95, 49-68.

(39) Trześniewski, B. J.; Digdaya, I. A.; Nagaki, T.; Ravishankar, S.; Herraiz-Cardona, I.; Vermaas, D. A.; Longo, A.; Gimenez, S.; Smith, W. A. Near-Complete Suppression of Surface Losses and Total Internal Quantum Efficiency in $\mathrm{BiVO}_{4}$ Photoanodes. Energy Environ. Sci. 2017, 10, 1517-1529.

(40) Trześniewski, B. J.; Smith, W. A. Photocharged $\mathrm{BiVO}_{4}$ Photoanodes for Improved Solar Water Splitting. J. Mater. Chem. A 2016, 4, 2919-2926.

(41) Smekal, W.; Werner W. S. M.; Powell, C. J. Simulation of Electron Spectra for Surface Analysis (SESSA): a Novel Software Tool for Quantitative Auger-Electron Spectroscopy and X-ray Photoelectron Spectroscopy. Surf. Interface Anal. 2005, 37, 1059-1067.

(42) Yang, M.; Shrestha, N. K.; Hahn, R.; Schmuki, P. Electrochemical Formation of Bismuth Phosphate Nanorods by Anodization of Bismuth. Electrochem. Solid State Lett. 2010, 13, C5-C8.

(43) Zhang, Y.; Fan, H.; Li, M.; Tian, H. Ag/BiPO 4 Heterostructures: Synthesis, Characterization and Their Enhanced Photocatalytic Properties. Dalton Trans. 2013, 42, 13172-13178.

(44) Fulekar M. H.; Singh, A.; Dutta, D. P.; Roy, M.; Ballal, A.; Tyagi, A. K. Ag Incorporated Nano $\mathrm{BiPO}_{4}$ : Sonochemical Synthesis, Characterization and Improved Visible Light Photocatalytic Properties. RSC Adv. 2014, 4, 10097-10107.

(45) Wu, S.; Zheng, H.; Lian, Y.; Wu, Y. Preparation, Characterization and Enhanced Visible-Light Photocatalytic Activities of $\mathrm{BiPO}_{4} / \mathrm{BiVO}_{4}$ Composites. Mat. Res. Bull. 2013, 48, 2901-2907.

(46) Cao, J.; Xu, B.; Lin, H.; Chen, S. Highly Improved Visible Light Photocatalytic Activity of $\mathrm{BiPO}_{4}$ Through Fabricating a Novel p-n Heterojunction BiOI/BiPO ${ }_{4}$ Nanocomposite. Chem. Eng. Journal 2013, 228, 482-488.

(47) Hüfner, S. Photoelectron Spectroscopy Principles and Applications, $3^{\text {rd }}$ ed. (Springer-Verlag, Berlin, 2003).

(48) Li, Y.-H.; Gregory, S. Diffusion of Ions in Sea Water and in Deep-Sea Sediments, Geochim. Cosmochim. Acta, 1974, 38, 703-714.

(49) Wright, M. R.; An Introduction to Aqueous Electrolyte Solutions (John Wiley and Sons, Inc. West Sussex, 2007).

(50) Spencer, B. F.; Graham, D. M.; Hardman, S. J. O.; Seddon, E. A.; Cliffe, M. J.; Syres, K. L.; Thomas, A. G.; Stubbs, S. K.; Sirotti, F.; Silly, M. G. Et al. Time-Resolved Surface Photovoltage Measurements at n-Type Photovoltaic Surfaces: Si(111) and ZnO(1010). Phys. Rev. B, 2013, 88, 195301. 
(51) Salis, A.; Ninham, B. W. Models and Mechanisms of Hofmeister Effects in Electrolyte Solutions, and Colloid and Protein Systems Revisited. Chem. Soc. Rev. 2014, 43, 7358-7377.

(52) Eiberweiser, A.; Nazet, A.; Hefter, G.; Buchner, R. Ion Hydration and Association in Aqueous Potassium Phosphate Solutions. J. Phys. Chem. B 2015, 119, 5270-5281. 


\section{TOC Graphics}

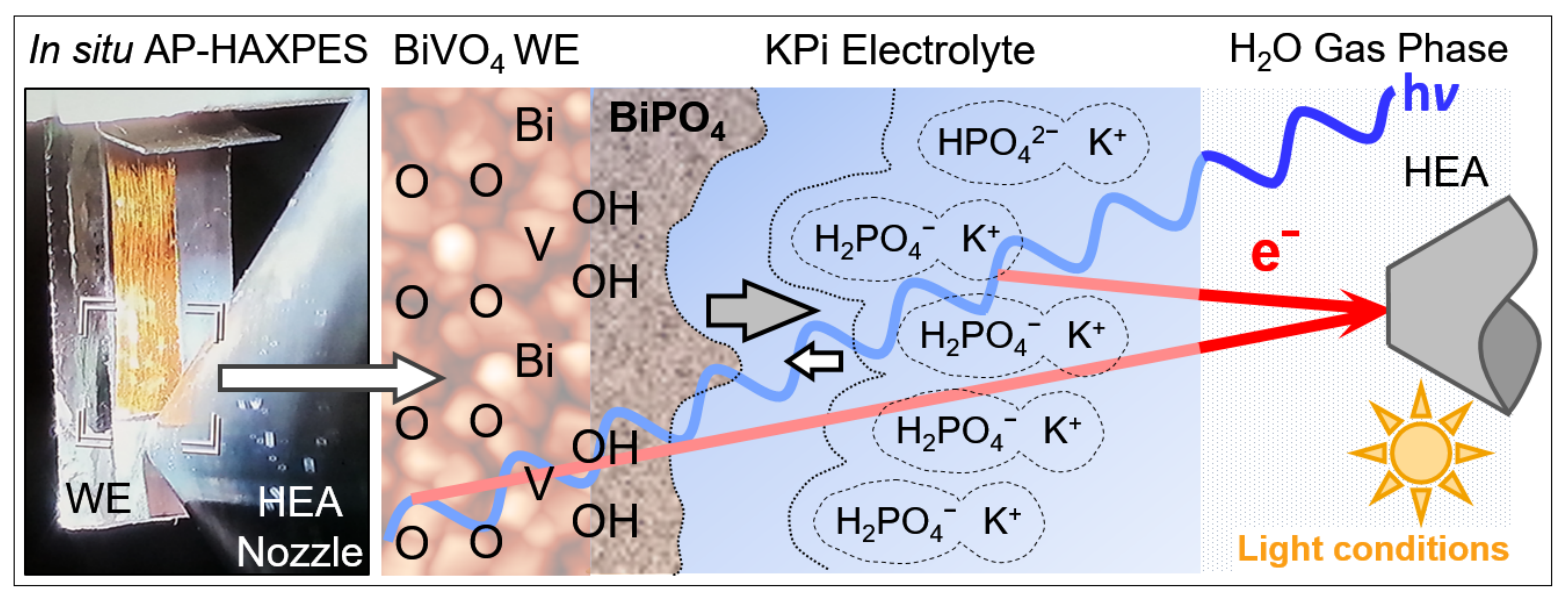

